\title{
Analysis on the polyphenols, flavonoids and antioxidant activities of broccoli
}

\author{
Qingqing Dong 1,a, Yaxin Jiang ${ }^{1, b}$, Qiutong Wang ${ }^{1, c}$, Minmin Liu ${ }^{1, d}$, Nan Wang ${ }^{1, e}$, \\ Hongpeng He ${ }^{1, \mathrm{f}}$, Hao Zhou ${ }^{1, \mathrm{~g}}$, Tong-Cun Zhang ${ }^{1, \mathrm{~h}}$ and Xuegang Luo ${ }^{1, \mathrm{i}, *}$ \\ ${ }^{1}$ Key Laboratory of Industrial Microbiology, Ministry of Education and Tianjin City, College of \\ Biotechnology, Tianjin University of Science and Technology \\ a2008dongqingqing@163.com, b815965816@qq.com, c619419926@qq.com, \\ d249878556@qq.com, ewn929@tust.edu.cn, fhehongpeng@tust.edu.cn, 9zhouhao@tust.edu.cn, \\ htony@tust.edu.cn, i,*luoxuegang@hotmail.com
}

Keywords: broccoli, polyphenols, flavonoids, antioxidant activities.

Abstract. This study aimed to investigate the content of polyphenols and flavonoids and the antioxidant activities of broccoli. In this study, the content of polyphenols and flavonoids in broccoli were detected by folin-ciocalteu colorimetric method and $\mathrm{NaNO} 2-\mathrm{Al}(\mathrm{NO} 3) 3-\mathrm{NaOH}$ colorimetric method. What's more, the antioxidant activities of broccoli were determined by DPPH and ABTS methods. The results showed that broccoli was rich in polyphenols and flavonoids and has good antioxidant capacity.

\section{Introduction}

Broccoli is a kind of high-grade health vegetables with high nutritional value and unique flavor, known as "vegetable crown". Its buds and leavves have abundant nutriment, rich in protein, carotene, $\mathrm{VC}, \mathrm{VB}$, minerals calcium, phosphorus and iron and so on $[1,2]$. It possesses both nourishing and healthcare functions. In addition, its edible parts are also rich in ascorbic acid, which can enhance the detoxification ability of liver and improve immunity; Polyphenols can effectively eliminate free radicals in the body, improve blood circulation, reduce cholesterol, inhibit low-density lipoprotein (LDL-C), cholesterol oxidation and so on [3-5].

Free radicals are harmful substances that are produced by oxidation. It attacks almost all cells in the body $[6,7]$. Cause damage to human tissues and organs, accelerate the aging of the body and cause disease [8]. Jerzy, Borowski [9] and Hilde H.Wijngaard [10] have studied the removal of DPPH free radical and reducing ability (FRAP) of broccoli polyphenols. The results show that broccoli polyphenols have strong antioxidant activity. This paper objected to determine the polyphenols, flavone and the antioxidation effect in broccoli.

\section{Materials and methods}

\subsection{Preparation of media}

Fresh broccoli were homogenized to prepare broccoli puree. And then add water, so that the quality and volume ratio of broccoli is $1: 2(\mathrm{~m} / \mathrm{v})$. To avoid the inactivation of the endogenous myrosinase, which hydrolyses glucosinolates into numerous biologically active products, broccoli puree was not sterilized by high temperature. $\mathrm{Tt}$ was filtered with $0.22 \mu \mathrm{m}$ microporous membrane to remove bacteria and then stored at $20{ }^{\circ} \mathrm{C}$ before use.

\subsection{Determination of polyphenols content}

The content of polyphenols in broccoli was determined by Folin-Ciocalteu colorimetric method. 0.2 $\mathrm{mL}$ broccoli juice were add to a $10 \mathrm{~mL}$ volumetric flask, and then add $4 \mathrm{~mL} \mathrm{10 \%} \mathrm{Folin} \mathrm{phenol} \mathrm{reagent,}$ shake, standing for $5 \mathrm{~min}$. adding $0.3 \mathrm{~mL} 20 \% \mathrm{Na}_{2} \mathrm{CO}_{3}$ after adding water to volume $10 \mathrm{~mL}$. After 
standing for $1.5 \mathrm{~h}$ at room temperature measured absorbance value at $\lambda \max =710 \mathrm{~nm}$, reference reagent blank.

\subsection{Determination of flavone content}

The content of flavonoids in broccoli was determined by $\mathrm{NaNO}_{2}-\mathrm{Al}\left(\mathrm{NO}_{3}\right)_{3}-\mathrm{NaOH}$ colorimetric method. Take a certain amount of broccoli to a $10 \mathrm{~mL}$ volumetric flask, add $90 \%$ ethanol up to $5 \mathrm{~mL}$, $0.4 \mathrm{~mL}, 5 \% \mathrm{NaNO}_{2}$, and after standing for $6 \mathrm{~min}$ with $0.4 \mathrm{~mL} 10 \% \mathrm{Al}\left(\mathrm{NO}_{3}\right)_{3}$, shake. Standing for 8 min after adding $4.2 \mathrm{~mL} 4 \% \mathrm{NaOH}$, mixing. After standing for $15 \mathrm{~min}$ measured absorbance value at $\lambda \max =510 \mathrm{~nm}$, reference reagent blank.

\subsection{The method of DPPH}

The sample and DPPH working solution were shaken and mixed, placed in the dark at $37{ }^{\circ} \mathrm{C}$ for 25 min, measured at $514 \mathrm{~nm}$ absorbance; Take the water and DPPH working solution shake mix, under the same conditions, measured absorbance, calculate the removal rate of DPPH for samples.

\subsection{The method of ABTS}

The sample and ABTS working solution were shaken and mixed, placed in the dark at $37{ }^{\circ} \mathrm{C}$ for 10 min, measured at $734 \mathrm{~nm}$ absorbance; Take the water and ABTS working solution shake mix, under the same conditions, measured absorbance, calculate the removal rate of ABTS for samples.

\subsection{Statistical analysis}

Data were presented as means \pm SD from at least three separate experiments. The significant difference was examined using the Student's t test. The minimal level of significance was $\mathrm{P}<0.05$.

\section{Results and discussion}

\subsection{The content of polyphenols and flavonoids}

We separately use gallic acid and rutin as standard product to determine the content of polyphenols and flavonoids in broccoli, measured standard curve shown in Figure 1. The regression equation was obtained by the regression equation of gallic acid or rutin concentration and absorbance, as follows: $y$ $=1.6438 \mathrm{x}+0.015, \mathrm{y}=0.0146 \mathrm{x}-0.159$, and the correlation coefficient was $\mathrm{R} 2=0.9974, \mathrm{R} 2=$ 0.9915 .
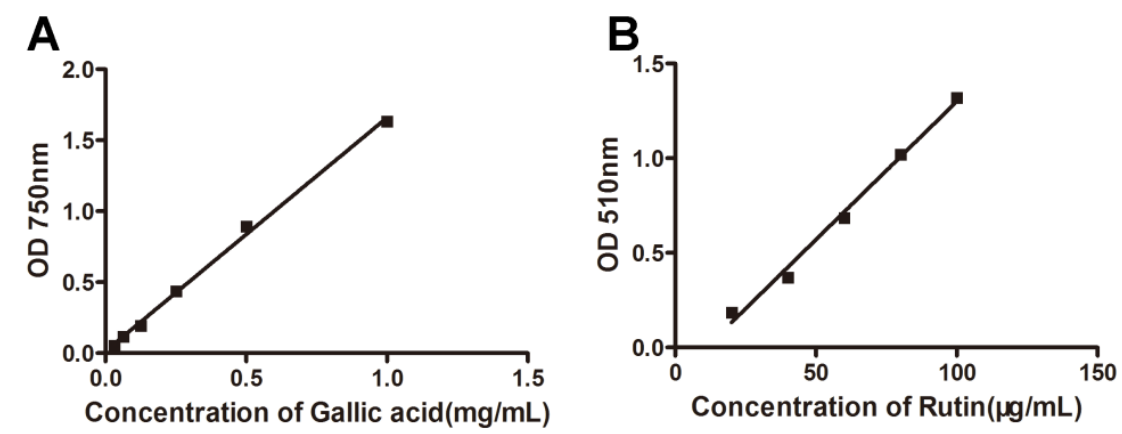

Fig. 1. The drawing of the standand curve of gallic acid and rutin. (A)The standand curve of gallic acid. (B)The standand curve of rutin.

According to the above standard curve, calculate the broccoli polyphenols, flavonoids content, the results shown in Figure 2. 1g fresh broccoli containing polyphenols and flavonoids separately were 8.42 and $1.10 \mathrm{mg}$. 


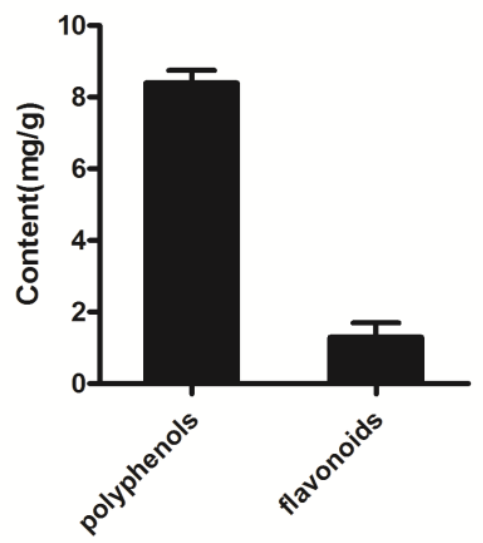

Fig. 2. The content of polyphenols and flavonoids in broccoli.

\subsection{Determination of antioxidant activity of broccoli by DPPH and ABTS}

We separately use Vc and Trolox as DPPH and ABTS method of the standard product to determine the antioxidant activity of broccoli, measured standard curve shown in Figure 3. The regression equation was obtained by the regression equation of $\mathrm{Vc}$ or Trolox concentration and inhibition, as follows: $\mathrm{y}=1.6438 \mathrm{x}+0.015, \mathrm{y}=0.0146 \mathrm{x}-0.159$, and the correlation coefficient was $\mathrm{R} 2=0.9974$, $\mathrm{R} 2=0.9915$.
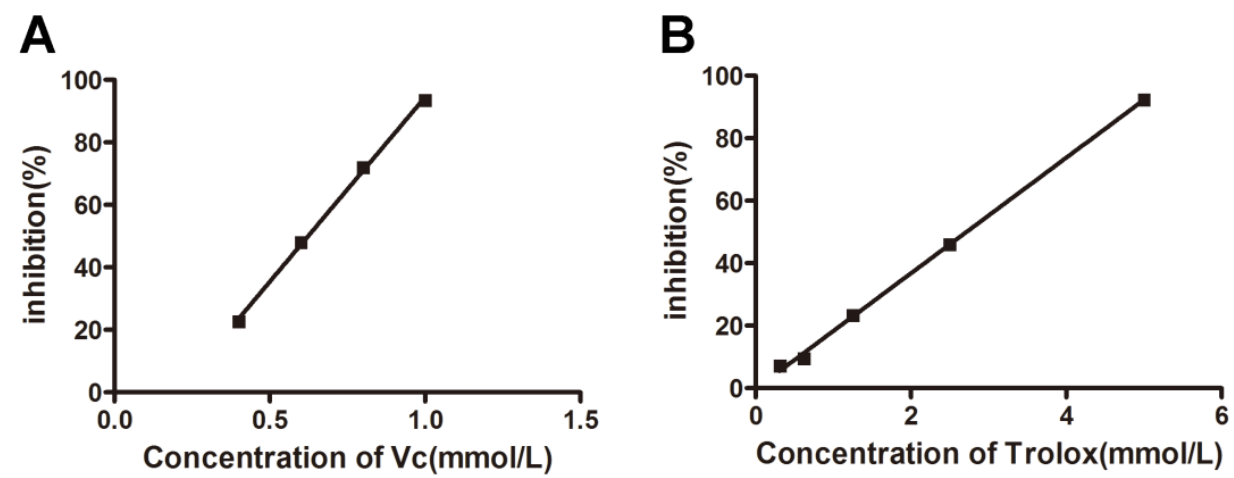

Fig. 3. The drawing of the standand curve of DPPH and ABTS methods. (A)The standand curve of DPPH method. (B)The standand curve of ABTS method.

According to the above standard curve, calculate the antioxidant activity of broccoli, the results shown in Figure 4. The antioxidant capacity of $1 \mathrm{~g}$ of fresh broccoli was 137.8 and $14.74 \mathrm{mmol} / \mathrm{L} / \mathrm{g}$, respectively, measured by DPPH and ABTS methods.

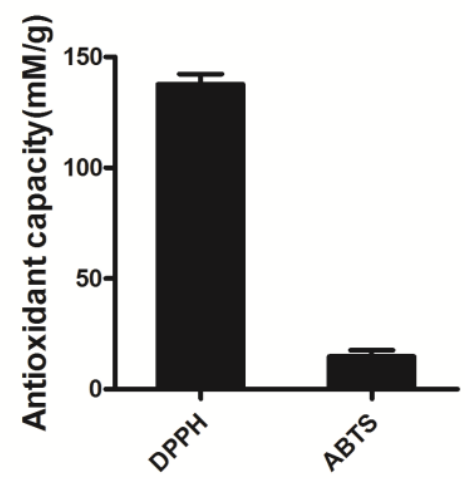

Fig. 4. The antioxidant capacity of broccoli

\section{Conclusion}

This study investigated the content of polyphenols and flavonoids and the antioxidant activities of Broccoli. The results show that broccoli is rich in polyphenols and flavonoids, the content of total 
polyphenols and flavonoid in broccoli were 8.42 and $1.10 \mathrm{mg} / \mathrm{g}$ separately. At the same time, broccoli also has good antioxidant capacity, per unit mass of broccoli's antioxidant capacity were (TEAC) 137.8 and (VCEAC) $14.76 \mathrm{mmol} / \mathrm{L} / \mathrm{g}$ separately measured by DPPH and ABTS methods.

\section{Acknowledgement}

This work was supported by grants from the National Natural Science Foundation of China (31470816, 31300642), the College Students' Innovation and Entrepreneurship Training Program of Tianjin (NO. 201510057057) and the Young Teachers' Innovation Fund of Tianjin University of Science and Technology (2016LG06).

\section{References}

[1] F. Xu, Z. Yang, X. Chen, P. Jin, X. Wang and Y. Zheng, 6-Benzylaminopurine delays senescence and enhances health-promoting compounds of harvested broccoli, J Agric Food Chem, vol. 60, pp. 234-240, 2012.

[2] H. R. Vasanthi, S. Mukherjee and D. K. Das, Potential health benefits of broccoli- a chemico-biological overview, Mini Rev Med Chem, vol. 9, pp. 749-759, 2009.

[3] C. N. Armah, C. Derdemezis, M. H. Traka, J. R. Dainty, J. F. Doleman, S. Saha, W. Leung, J. F. Potter, J. A. Lovegrove and R. F. Mithen, Diet rich in high glucoraphanin broccoli reduces plasma LDL cholesterol: Evidence from randomised controlled trials, Mol Nutr Food Res, vol. 59, pp. 918-926, 2015.

[4] H. B. Carvacho, C. Perez, G. Zuniga and A. Mahn, Effect of methyl jasmonate, sodium selenate and chitosan as exogenous elicitors on the phenolic compounds profile of broccoli sprouts, J Sci Food Agric, vol. 94, pp. 2555-2561, 2014.

[5] K. M. Ku, E. H. Jeffery and J. A. Juvik, Optimization of methyl jasmonate application to broccoli florets to enhance health-promoting phytochemical content, J Sci Food Agric, vol. 94, pp. 2090-2096, 2014.

[6] B. Halliwell, Free radicals and antioxidants: updating a personal view, Nutr Rev, vol. 70, pp. 257-265, 2012.

[7] J. Q. Wu, T. R. Kosten and X. Y. Zhang, Free radicals, antioxidant defense systems, and schizophrenia, Prog Neuropsychopharmacol Biol Psychiatry, vol. 46, pp. 200-206, 2013.

[8] A. Chaudhary, U. Sharma, A. P. Vig, B. Singh and S. Arora, Free radical scavenging, antiproliferative activities and profiling of variations in the level of phytochemicals in different parts of broccoli (Brassica oleracea italica), Food Chem, vol. 148, pp. 373-380, 2014.

[9] J. Borowski, A. Szajdek, E. J. Borowska, E. Ciska and H. Zieliński, Content of selected bioactive components and antioxidant properties of broccoli (Brassica oleracea L.), European Food Research and Technology, vol. 226, pp. 459-465, 2008.

[10] H. H. Wijngaard, C. R. Le and N. Brunton, A survey of Irish fruit and vegetable waste and by-products as a source of polyphenolic antioxidants, Food Chemistry, vol. 116, pp. 202-207, 2009. 